\title{
A EXPANSÃO DO ENSINO SUPERIOR NO BRASIL SOB INFLUÊNCIA DA DEClARAÇÃo de BOLONHA: PRIMEIRAS APROXIMAÇõeS
}

\author{
THE EXPANSION OF HIGHER EDUCATION IN BRAZIL UNDER THE INFLUENCE OF THE \\ BOLOGNA DECLARATION: FIRST APPROACHES \\ LA EXPANSIÓN DE LA ENSEÑANZA SUPERIOR EN BRASIL BAJO LA INFLUENCIA DE LA \\ DECLARACIÓN DE BOLONIA: PRIMERAS APROXIMACIONES
}

\section{Maria de Lourdes Pinto de Almeida ${ }^{1}$ Altair Fávero ${ }^{2}$ Carina Tonieto 3}

\begin{abstract}
RESUMO
O presente artigo tem por intenção investigar se o atual cenário de expansão do ensino superior no Brasil reflete os princípios e diretrizes educacionais postas pela Declaração de Bolonha. O estudo parte da hipótese que as políticas atuais de expansão do ensino superior no país revelam influências mundiais em relação ao papel do Estado, das Universidades e dos Empresários, sendo um destes documentos a Declaração de Bolonha de 19 de junho de 1999. Desse modo, compreender o conteúdo deste documento nos daria alguns indicativos para compreender os pressupostos que orientam os contornos das políticas educacionais brasileiras dos últimos treze anos, tendo como referência os dados publicados pelo Ministério da Educação no período de 2000 a 2011. Os autores defendem a tese de que a expansão do ensino superior brasileiro protagonizado pela iniciativa privada reflete as proposições, mesmo que parciais, da Declaração de Bolonha, já que esta é uma tentativa de reforma do cenário educacional europeu com vistas a aumentar a competitividade no Sistema Europeu do Ensino Superior. PALAVRAS-CHAVE: Declaração de Bolonha. Expansão do ensino superior. Políticas públicas na educação. Políticas de educação superior.
\end{abstract}

\begin{abstract}
The intention of this article is to investigate the current scenario of expansion of higher education in Brazil reflects the educational principles and guidelines laid down by the Bologna Declaration. The study starts from the hypothesis that the current policies of expansion of higher education in the country reveal global influences on the role of the State, the Universities and Entrepreneurs, one of these documents to the Bologna Declaration of 19 June 1999 Thus, understand the contents of this document would give us some pointers understand the assumptions that guide the contours of Brazilian educational policies of the last thirteen years, with reference to data published by the Ministry of Education from 2000 to 2011 the authors advocate the thesis that the expansion of higher education in Brazil led by the private sector reflects the propositions, even partial, of the Bologna Declaration, since this is an attempt to reform the European educational landscape in order to increase competitiveness in the European System of Higher Education.
\end{abstract}

KEYWORDS: Bologna Declaration. Expansion of higher education. Public policy in education. Policies for

\footnotetext{
${ }^{1}$ Doutora em Filosofia, História e Educação pela Universidade Estadual de Campinas e pós-doutora em Políticas Educacionais pela USP e em Ciência Tecnologia e Sociedade pela Unicamp. Pesquisadora do GIEPES - Grupo Internacional de Estudos e Pesquisas em Ensino Superior Docente pesquisadora do PPGEdu da Unoesc Ddiretora da Rede Ibero-americana de Pesquisas em Políticas e Processos de Educação Superior - RIPPES sediada na Unoesc. E-mail: malu04@gmail.com

${ }^{2}$ Doutor em Educação pela Universidade Federal do Rio Grande do Sul; Pós-Doutor pela Universidad Autónoma del Estado de México. Professor titular III e pesquisador da Universidade de Passo Fundo. Pesquisador da Rede de Estudos e Pesquisas em Ensino Superior (REPES - Furg). E-mail: altairfavero@gmail.com

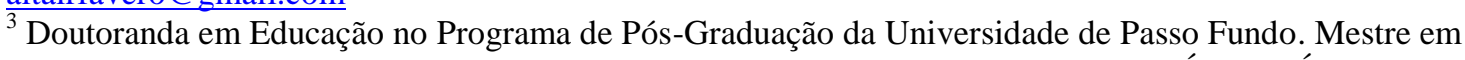
Educação pela Universidade de Passo Fundo/RS. Professora do curso de Filosofia e Área de Ética e Conhecimento na Universidade de Passo Fundo/UPF. E-mail: tornieto.carina@ gmail.com
}

Recebido em: 21/09/2015 - Aceito em: 02/12/2015.

\begin{tabular}{l|l|l|l|l|l|l} 
(C) Rev. Inter. Educ. Sup. & Campinas, SP & v.1 & n.2 & p.182-198 & out./dez. 2015 & ISSN 2446-9424
\end{tabular}


higher education.

\section{RESUMEN}

El presente artículo tiene por intención investigar si el actual escenario de expansión de la enseñanza superior en Brasil refleja los principios y directrices educacionales puestas por la Declaración de Bolonia. El estudio parte de la hipótesis que las políticas actuales de expansión de la enseñanza superior en el país revelan influencias mundiales con relación al papel del Estado, de las Universidades y de los Empresarios, siendo uno de estos documentos la Declaración de Bolonia del 19 de junio de 1999. De ese modo, comprender el contenido de este documento nos daría algunos indicativos para entender los supuestos que orientan los contornos de las políticas educacionales brasileñas de los últimos trece años, teniendo como referencia los datos publicados por el Ministerio de la Educación en el periodo de 2000 a 2011. Los autores defienden la tesis de que la expansión de la enseñanza superior brasileño protagonizada por la iniciativa privada refleja las proposiciones, aunque parciales, de la Declaración de Bolonia, ya que este es un intento de reforma del escenario educacional europeo con vistas a incrementar la competencia en el Sistema Europeo de Enseñanza Superior.

PALABRAS CLAVE: Declaración de Bolonia. Expansión de la enseñanza superior. Políticas públicas en la educación. Políticas de educación superior.

\section{INTRODUÇÃO}

\section{"Uma nova epistemologia da Educação Superior surge no século 21. Esta epistemologia sustenta as razões pelas quais as universidades devem trilhar caminhos globais e internacionais, redesenhar seu perfil em direção aos mercados e desenvolver modalidades de capitalismo acadêmico". (Denise Leite e Maria Elly H. Genro, 2012)}

Este texto pretende discutir o cenário de expansão do ensino superior no Brasil e os seus possíveis reflexos nos princípios e diretrizes educacionais postas pela Declaração de Bolonha. Partimos do pressuposto que as políticas de expansão do ensino superior no país revelam influências mundiais em relação ao papel do Estado, das Universidades e dos Empresários, sendo um destes documentos a Declaração de Bolonha de 19 de junho de 1999. Desse modo, compreender o conteúdo deste documento nos daria alguns indicativos para compreender os pressupostos que orientam os contornos das políticas educacionais brasileiras dos últimos treze anos, tendo como referência os dados publicados pelo Ministério da Educação no período de 2000 a 2011.

Frente às transformações econômicas das últimas décadas, a Universidade pública brasileira sofreu os impactos da globalização. O enfraquecimento do Estado, principalmente com a crise fiscal e o prevalecimento de políticas de redução da ação e do investimento do governo no setor social, especialmente na Educação Superior, a Universidade pública brasileira sofreu com a redução dos investimentos resultantes de uma política asfixiante para o setor. O setor acadêmico passou a ser pressionado no sentido de buscar investimentos próprios, principalmente com parcerias e serviços prestados ao setor privado. Nesse sentido, as transformações mais recentes ocorridas nas Universidades têm sido vistas como índices de um novo modelo de relação da Universidade com a sociedade, em especial com o setor privado. Nosso objetivo é demonstrar que a globalização do sistema de pesquisa e

\begin{tabular}{l|l|l|l|l|l|l} 
(C) Rev. Inter. Educ. Sup. & Campinas, SP & v.1 & n.2 & p.182-198 & out./dez. 2015 & ISSN 2446-9424 \\
\hline
\end{tabular}


desenvolvimento se dá no interior de uma profunda reestruturação do sistema mundial de produção do conhecimento, pois se trata de um processo orquestrado pelas corporações multinacionais. Nesse sentido, com a globalização há uma apropriação, um domínio e um controle corporativo do conhecimento gerado pela ciência acadêmica. Com isso, a Academia tende a transformar-se cada vez mais em funcionalista, no sentido de ser regida por critérios comerciais. Opera-se o que se denomina de mudança no ethos acadêmico. Isso devido ao fato de que a Universidade Pública perde cada vez mais a sua antiga função intelectualcultural-social, para assumir um caráter mais empresarial.

Procuramos, portanto, compreender as transformações pelas quais passa a Academia Pública Brasileira a partir das transformações da economia global. Segundo estas mudanças, novas exigências são feitas aos setores de Pesquisa \& Desenvolvimento e a descentralização apresenta-se como a principal característica dos novos rumos impostos às empresas pelo processo de globalização da economia. A descentralização do $\mathrm{P} \& \mathrm{D}$ vincula-se inicialmente ao esforço de racionalização da pesquisa efetuado pelas multinacionais, visando evitar a duplicação do esforço na produção de pesquisas e novas estratégias de desenvolvimento, sendo uma de suas marcas a redução de custos por meio de fusões e associações empresarias. Esse processo tem feito aparecer redes organizacionais, o que levou a descentralização da pesquisa básica. A característica principal da descentralização é a organização em rede ou sistema de interdependência entre unidades de Pesquisa \& Desenvolvimento. A Universidade acaba por ser cooptada nessa rede pelo setor econômico.

Segundo Licha (1996, p. 27), somente as firmas mais poderosas investem em pesquisa básica. Somente elas teriam objetivos a longo prazo e teriam meios para investir nesse tipo de pesquisa. O "desenvolvimento", característico do processo de criação e adequação dos produtos ao mercado, se dá no interior das empresas, onde se concentra a atividade mais prática e imediata. Já a pesquisa tende a ser feita a partir de parcerias externas e com a colaboração entre empresas. A tendência no seio acadêmico seria a de que os pesquisadores tornar-se-iam cada vez mais "consultores altamente especializados" do que intelectuais trabalhando no campo da pesquisa fundamental.

No Brasil, neste início de século XXI, os intelectuais que estão atuando no stricto sensu, tem vivido uma era denominado por alguns historiadores da educação superior, como era do produtivismo acadêmico. Sob a coordenação e orientação da Coordenação de Aperfeiçoamento de Pessoal de Nível Superior (CAPES) estabelece-se uma pressão sobre produção do conhecimento regida pela avaliação quantitativa de papers escritos e publicados. O processo dinâmico que se dá no sistema de educação superior traz modificações nas atribuições que são cobradas das Universidades, fazendo da produção do conhecimento uma mercantilização da Educação, onde a qualidade do ensino oferecido pela Instituição é determinada pela quantidade de publicação de seus intelectuais.

O conhecimento produzido pela Universidade diz-se público pelo fato de se engendrar dentro de instituição não privada. Contudo, dentro do novo ethos acadêmico, o conhecimento

\begin{tabular}{l|l|l|l|l|l|l} 
(C) Rev. Inter. Educ. Sup. & Campinas, SP & v.1 & n.2 & p.182-198 & out./dez. 2015 & ISSN 2446-9424
\end{tabular}


já em sua origem e destino tende a trazer a marca do interesse privado. Os interesses privados referem-se às forças do mercado, representadas pela demanda das empresas. Nesse sentido não se poderia falar de uma socialialização do saber, mas de uma apropriação. A apropriação ocorre na medida em que o sistema de patentes e os convênios conferem a alguns grupos o direito exclusivo sobre os saberes produzidos na Universidade pública. Devemos lembrar, porém que a apropriação do conhecimento cientifico não é um privilégio do novo ethos acadêmico. Por mais público que pareça o modelo merthoniano ou da ciência 'autônoma' os seus resultados gerais, ou seja, os interesses aos quais a academia atendeu sempre foram os de uma elite. O que caracteriza a nova forma de apropriação do conhecimento é a abertura ao mercado que redefine as relações entre os "produtores" do conhecimento e os seus "consumidores". Dentro desse novo ethos acadêmico, os interesses comerciais tendem a agenciar a investigação científica. $O$ grande debate ideológico atual gira em torno da legitimidade desse processo.

Ao se reestruturar conforme a lógica do mercado global, a Universidade tende a dar mais ênfase às pesquisas aplicadas, bem como a estancar investimentos e áreas de pesquisas não viáveis economicamente. Com isso a Universidade pode contornar as dificuldades de seu financiamento, que se tornou problemático com a política de reestruturação do próprio Estado conforme a lógica da globalização. O desaparecimento do espaço público, caracterizado pela contínua perda de poder decisório, soberania, do estado-nação, se reflete na Universidade pública fundamentalmente na busca de novas fontes de financiamento. Contudo essa tendência de mercantilização do conhecimento pode ser revertida. No processo de agenciamento do conhecimento científico, a Universidade pública pode também buscar alternativas para não se reduzir a um mero balcão de tecnologia, em que apenas se agencia convênios entre pesquisadores mantidos com fundos públicos.

Vimos que a principal característica dos tempos atuais marca-se pela globalização. A globalização caracteriza-se, sobretudo pela liberação dos mercados nacionais. Nesse novo cenário mundial, perdem força os trabalhadores, devido à flexibilização do trabalho, ao enfraquecimento dos sindicatos e ao desmonte do sistema de proteção social, fundado em direitos arduamente adquiridos. Trata-se, na verdade, de um processo que atinge diretamente os Estados Nação que bem ou mal garantiam os direitos e promovia certas garantias mínimas conforme as políticas de Bem Estar Social. O público enquanto expressão do precário contrato entre capital e trabalho mediado pelo Estado tende a desaparecer com a globalização. O Estado de bem estar social representou uma força elevada de manutenção do referido contrato. Através dele o capital negociou, cedeu, a fim de manter-se enquanto tal. Com a globalização, o capital recobra sua força e retoma as posições que havia perdido, impondo uma nova forma de espoliação que escapa aos controles nacionais. Ainda que grande parte da população de nações como a brasileira não tenha tido acesso aos benefícios públicos, o Estado manteve-se como esse espaço susceptível de ser ocupado por tendências capazes de ampliar a participação da população nos benefícios conquistados pela nossa civilização. É nesse contexto que se dá a expansão da Educação Superior no Brasil que será descrita abaixo. 


\section{O contexto de expansão da Educação Superior no Brasil}

O contexto que buscaremos caracterizar compreender o período de 2001 a 2011, o qual consideramos significativo, por representar uma década de expansão da Educação Superior brasileira notadamente marcada pelos princípios da globalização e da produção do conhecimento submetida aos interesses do capital.

O resumo técnico do censo de educação superior relativo ao ano 2011, publicado pelo Ministério da Educação em abril de 2013, aponta números expressivos em relação ao cenário atual da educação superior no Brasil. Contaríamos em números oficiais com: 2.365 instituições de ensino superior ${ }^{4}$, sendo que $88,0 \%$ são privadas ${ }^{5}$ e somente $12,0 \%$ públicas; 6.739.689 matrículas em cursos de graduação presenciais e à distância, sendo que 26,3\% estão em instituições públicas e 73,7\% nas instituições privadas. Do montante de matrículas $53,9 \%$ estão nas Universidades ${ }^{6}, 13,7 \%$ nos Centros Universitários ${ }^{7}, 30,9 \%$ nas Faculdades $^{8}$ e $1,5 \%$ nos IFs $^{9}$ e Cefets $^{10}$ (INEP, 2013). Tais números apontam para o aumento significativo

\footnotetext{
${ }^{4}$ Desse montante $84,7 \%$ são faculdades, $8,0 \%$ são Universidades, 5,6\% são centros universitários e 1,7\% representam a soma de institutos federais de educação, ciência e tecnologia (IFs) e de centros federais de educação tecnológica (Cefets). Segundo a Portaria Normativa $n^{\circ}$ 40, de 12 de dezembro de 2007, as instituições de educação superior, de acordo com sua organização acadêmica, são classificadas como: I - faculdades; II centros universitários; III - Universidades; IV - institutos federais de educação, ciência e tecnologia; e V centros federais de educação tecnológica.

${ }^{5}$ Segundo Portaria Normativa $\mathrm{n}^{\circ}$ 40, de 12 de dezembro de 2007, as instituições de ensino superior brasileiras são classificadas de acordo com sua categoria administrativa em públicas e privadas. As instituições públicas subdividem-se em: Federal- instituição mantida pelo Poder Público Federal, com gratuidade de matrículas e mensalidades; Estadual- instituição mantida pelo Poder Público Estadual, com gratuidade de matrículas e mensalidades; Municipal- instituição mantida pelo Poder Público Municipal, com gratuidade de matrículas e mensalidades. As instituições privadas subdividem-se em: com fins lucrativos - instituição mantida por ente privado, com fins lucrativos; sem fins lucrativos não beneficente- instituição mantida por ente privado, sem fins lucrativos; pode ser confessional ou comunitária, conforme o art. 20 da LDB; beneficente: instituição mantida por ente privado, sem fins lucrativos, detentora de Certificado de Assistência Social, nos termos da legislação própria. Pode ser confessional ou comunitária. Especial (art. 242 da Constituição Federal)- instituição educacional oficial criada por lei estadual ou municipal e existente na data da promulgação da Constituição Federal, que não seja total ou preponderantemente mantida com recursos públicos, portanto não gratuita.

${ }^{6}$ As Universidades são instituições pluricurriculares de formação dos quadros profissionais de nível superior, de pesquisa, de extensão e de domínio e cultivo do saber humano, que se caracterizam por: I - produção intelectual institucionalizada mediante o estudo sistemático de temas e problemas mais relevantes tanto do ponto de vista científico e cultural quanto regional e nacional; II - um terço do corpo docente, pelo menos, com titulação acadêmica de mestrado ou doutorado; III - um terço do corpo docente em regime de tempo integral (Lei $\mathrm{n}^{\circ}$ 9.394, de 20 de dezembro de 1996).

${ }^{7}$ Os centros universitários são instituições de ensino superior pluricurriculares que se caracterizam pela excelência do ensino oferecido, pela qualificação do seu corpo docente e pelas condições de trabalho acadêmico oferecidas à comunidade escolar. São requisitos de atendimento por essas instituições: I - um quinto do corpo docente em regime de tempo integral; e II - um terço do corpo docente, pelo menos, com titulação acadêmica de mestrado ou doutorado (Decreto $\mathrm{n}^{\circ}$ 5.786, de 24 de maio de 2006)

${ }^{8}$ As faculdades incluem institutos e organizações equiparadas, nos termos do Decreto $\mathrm{n}^{\circ} 5.773$, de 9 de maio de 2006.

${ }^{9}$ Os institutos federais de educação, ciência e tecnologia (IFs) são instituições de educação superior, básica e profissional, pluricurriculares e multicampi, especializados na oferta de educação profissional e tecnológica nas diferentes modalidades de ensino, com base na conjugação de conhecimentos técnicos e tecnológicos com as suas práticas pedagógicas. No âmbito da educação superior, equiparam-se às Universidades federais para efeitos regulatórios (Lei n $\mathrm{n}^{\mathrm{1}} 1.892$, de 29 de dezembro de 2008)
}

\begin{tabular}{l|l|l|l|l|l|l} 
(c) Rev. Inter. Educ. Sup. & Campinas, SP & v.1 & n.2 & p.182-198 & out./dez. 2015 & ISSN 2446-9424
\end{tabular}


do número de instituições de ensino superior em relação ao ano de 2001, onde contávamos com 1.391 instituições de ensino superior ${ }^{11}$ sendo que destas $13,2 \%$ são públicas e $86,8 \%$ privadas; o número de matrículas é de 3.036.113, sendo 31,3\% em instituições públicas e 68,9\% em instituições privadas. Do montante de matrículas 64,6\% estão nas Universidades, 11,1\% em Centros Universitários, 23,6\% em Faculdades e 0,7\% em Ifs e Cefets (INEP, 2012).

Destacam-se nesses dez anos o nascimento de 974 instituições de ensino superior, porém não há uma grande variação no percentual de instituições públicas (13,2\% em 2001 para $12 \%$ em 2011) e privadas (86,08\% em 2001 para $88 \%$ em 2011), destacando-se, desse modo, a hegemonia do número de instituições privadas em relação às públicas. Por outro lado, o número de matrícula sofre um aumento significativo, aumentando em mais de 50\% nesses dez anos (de 3.036.113 em 2001 para 6.739 .689 em 2011), porém diminui o percentual de matrículas nas instituições públicas (de 31,3\% em 2001 para 26,3\% em 2011) e aumenta o número de matrículas nas instituições privadas (de 68,9\% em 2001 para 73,7\% em 2011), permanecendo, desse modo, a grande maioria das matrículas em instituições privadas. Além disso, diminui o número de matrículas nas Universidades (de 64,6\% em 2001 para $53,9 \%$ em 2011) e aumenta o número de matrículas nos centros universitários (de $11 \%$ em 2001 para 13,7 em 2011), nas faculdades (23,6\% em 2001 para 30,09\% em 2011) e nos IFs e Cefets (de a,7\% em 2001 para 1,5\% em 2011). A diminuição de 10,7\% das matrículas nas Universidades se diluiu no aumento de 2,6\% nos centros universitários, 7,3\% nas faculdades e $0,8 \%$ nas IFs e Cefets.

A respeito dos dados de 2011 cabe destacar que na esfera pública contamos com 86,7\% de Universidades, 0,9\% de Centros Universitários, 7,2\% de Faculdades e 5,2\% de Ifs e Cefets. Na esfera privada, por sua vez, contamos com 37,4\% de Universidades; $18,3 \%$ de Centros Universitários, 44,3\% de Faculdades. A partir de tais dados é possível perceber que, no contexto de expansão da educação superior brasileira, as Universidades, em sua grande maioria, estão sob a égide do poder público, ao passo que os Centros Universitários e Faculdades estão predominantemente vinculados ao setor privado.

Percebe-se, desse modo, que apesar de os dados apresentados nesse recorte de dez anos apontarem incisivamente para a expansão da educação privada no Brasil, sendo ela a responsável pela ampliação significativa do número de matrículas, ela se dá pelo aumento significativo dos Centros Universitários e Faculdades. De outro lado aumenta-se

\footnotetext{
${ }^{10}$ Os centros federais de educação tecnológica (Cefets) têm por finalidade formar e qualificar profissionais no âmbito da educação profissional e tecnológica, nos diferentes níveis e modalidades de ensino, para os diversos setores da economia, bem como realizar pesquisa aplicada e promover o desenvolvimento tecnológico de novos processos, produtos e serviços, em estreita articulação com os setores produtivos e a sociedade, especialmente de abrangência local e regional, oferecendo mecanismos para a educação continuada (Decreto $\mathrm{n}^{\circ} 5.224$, de $1^{\circ}$ de outubro de 2004). Conforme a Portaria Normativa $n^{\circ} 40$, para efeitos regulatórios, os Cefets equiparam-se aos centros universitários.

${ }^{11}$ Desse montante $82,2 \%$ são faculdades, $11,2 \%$ são Universidades, $4,7 \%$ são centros universitários e $1,9 \%$ são os IFs e Cefets.
} 
consideravelmente o número de matrículas no país, porém diminui-se o número de matrículas nas Universidades, ainda em sua maioria, de responsabilidade do poder público. Se de um lado diminui as matrículas nas Universidades Públicas, de outro, aumentam as matrículas nos Institutos Federais de Educação, Ciência e Tecnologia (IFs) e nos Centros Federais de Educação Tecnológica (Cefets), que por serem muito jovens, ocupam ainda uma pequena faixa da educação superior pública. Tais proporções nos levam a perguntar: Por que as Universidades, com sua tímida expansão, continuam, em sua maioria, públicas e as Faculdades e Centros Universitários, com sua vistosa expansão, em sua maioria, privados? Que tal cenário é o reflexo das políticas públicas educacionais e econômicas nacionais, articuladas com as políticas educacionais e econômicas internacionais, não resta dúvida, assim como, que pelo fato de nossa expansão ser recente e a imposição de rigorosos critérios de avaliação às instituições, torna a elevação para a categoria de Universidade demorada e custosa financeiramente para os Centros Universitários. Porém, será que tal cenário de expansão centrado no ensino, reflete alguns princípios da Declaração de Bolonha de 1999?

Buscaremos investigar no presente texto se o atual cenário de expansão da Educação Superior no Brasil reflete os princípios e diretrizes educacionais postas pela Declaração de Bolonha. Partiremos da hipótese que as políticas atuais de expansão do ensino superior no país revelam influências mundiais em relação ao papel do Estado, das Universidades e dos Empresários, sendo um destes documentos a Declaração de Bolonha de 19 de junho de 1999. Desse modo, compreender o conteúdo deste documento nos daria alguns indicativos para compreender os pressupostos que orientam os contornos das políticas educacionais brasileiras dos últimos treze anos, tendo como referência os dados publicados pelo Ministério da Educação no período de 2000 a 2011.

O contexto apontado acima do cenário educacional do ensino superior no Brasil é fruto de várias reformas ocorridas em nossas jovens instituições de ensino, originárias do Estatuto das Universidades Brasileiras de 1931. Esse movimento constitui a primeira reforma da educação superior brasileira; a segunda aconteceu em 1968 pela força da Lei 5.540/1968, promulgada pelo Presidente Costa e Silva, na qual a Educação Superior é chamada a contribuir para a modernização do país, flexibilização administrativa e formação de indivíduos para fomentar o desenvolvimento da nação; a terceira se daria com o Presidente Fernando Henrique Cardoso, com objetivo de dar conta dos desafios da educação superior brasileira do século XXI para dar conta, de um lado das demandas do mundo globalizado, e de outro, da falta de acesso, qualidade e financiamento da educação superior brasileira; a quarta é marcada pela Lei da Reforma da Educação Superior de 2006, proposta no governo do Presidente Luís Inácio Lula da Silva, a qual se encontra ainda em discussão.

É a partir desses cenários de tentativas de reforma que se situa a definição de reformas educativas que Dias Sobrinho (2009, p.127) indica como "construções de um quadro legal burocrático, geralmente proposto por políticos, para responder a determinados problemas e produzir efeitos mais ou menos coerentes com projetos mais amplos de um governo ou de um sistema de poder". Nessa direção é possível afirmar que o contexto atual

\begin{tabular}{l|l|l|l|l|l|l} 
(C) Rev. Inter. Educ. Sup. & Campinas, SP & v.1 & n.2 & p.182-198 & out./dez. 2015 & ISSN 2446-9424 \\
\hline
\end{tabular}


de expansão do ensino superior brasileiro não acontece por acaso. Ele é fruto de políticas educacionais voltadas para a diminuição da responsabilidade do Estado com a educação superior pública, principalmente a partir do governo de Fernando Henrique Cardoso, notadamente de cunho neoliberal, no qual o conceito de Estado Mínimo é aplicado na sua plenitude ao ensino superior. É desse período o notório sucateamento das Universidades Públicas e uma maior abertura do 'mercado educacional brasileiro' à iniciativa privada. Esta, por sua vez, aceitou de bom grado a abertura de tal fatia de atuação no mercado e lançou-se às novas oportunidades mercadológicas que surgiam num setor econômico pujante e num contexto educacional com grande demanda de acesso à Educação Superior. A iniciativa privada assume, então, o protagonismo da Educação Superior e o país experimenta um novo movimento que impulsiona o acesso e eleva substancialmente o número de matrículas. Ao poder público coube, nesse novo contexto, o papel de fiscalizar e regulamentar o ensino superior do país, de modo a garantir a expansão e firmar critérios de qualidade, voltados ao desenvolvimento intelectual, científico, econômico, tecnológico, social e cultural do país. Dias Sobrinho (1999) adverte que quando há um forte interesse econômico, nem sempre os valores acadêmicos voltados à formação e a produção do conhecimento são os que predominam. Nesse sentido vale indagar: A expansão da Educação Superior brasileira protagonizado pela iniciativa privada reflete as proposições, mesmo que parciais, da Declaração de Bolonha, já que esta é uma tentativa de reforma do cenário educacional europeu com vistas a aumentar a competitividade no Sistema Europeu do Ensino Superior?

\section{Os princípios da Declaração de Bolonha}

A Declaração de Bolonha consiste num documento assinado por 29 Ministros da Educação de países europeus, reunidos na cidade de Bolonha (Itália) em 19 de junho de 1999. É um documento que busca tratar, de forma cooperativa, das mudanças nas políticas do ensino superior dos países europeus, reconhecendo a importância da educação para o desenvolvimento das nações e, consequentemente, da comunidade europeia.

A justificativa para a consolidação do documento parte da afirmação de que "o processo Europeu, graças aos progressos extraordinários dos últimos anos, tornou-se numa realidade cada vez mais concreta e relevante para a União Europeia e os seus cidadãos" (BOLONHA, 1999, p.1), assim a iniciativa justifica-se pela contribuição que o desenvolvimento educacional poderá trazer para a comunidade europeia, em seu sentido mais amplo, e para os cidadãos em sentido restrito e concreto. É desse modo que será possível promover o "alargamento e o estabelecimento de relações cada vez mais profundas com outros países europeus” (DECLARAÇÃO DE BOLONHA, 1999, p.1) tornando tal proposta uma realidade. Tal iniciativa estaria em consonância com a crescente conscientização política e acadêmica mundial que reitera a necessidade e a importância das dimensões intelectual, cultural, social, científica e tecnológica para o desenvolvimento das nações.

Nessa direção, o documento registra que a busca pela consolidação da "Europa do Conhecimento" é reconhecidamente um "fator imprescindível ao crescimento social e

\begin{tabular}{l|l|l|l|l|l|l} 
(C) Rev. Inter. Educ. Sup. & Campinas, SP & v.1 & n.2 & p.182-198 & out./dez. 2015 & ISSN 2446-9424
\end{tabular}


humano, um elemento indispensável à consolidação e enriquecimento da cidadania Europeia", sendo capaz de promover espaços e oportunidades que possibilitarão aos seus cidadãos o desenvolvimento de "aptidões necessárias para enfrentar os desafios do novo milênio" aliando "a consciência de partilha dos valores" e a "pertença a um espaço social e cultural comum” (DECLARAÇÃO DE BOLONHA, 1999, p.1). Pode-se concluir a partir de tais afirmações que o objetivo é contribuir para a construção de uma Europa referência em produção do conhecimento, fato que contribuiria significativamente para o desenvolvimento social e humano, pois dotaria seus cidadãos de condições para enfrentar os desafios postos pelas demandas, principalmente econômicas, da era da globalização e competitividade mundial imposta pela inovação tecnológica e aberturas de novos mercados. Nessa direção a Declaração de Bolonha segue as trilhas do modelo global de desenvolvimento altamente dependente da inovação e de um padrão de competitividade marcado pela maleabilidade e flexibilidade. Tal contexto impele, por um lado a lógica a diferenciação pela capacidade de criação e de competição, mas por outro, devido a rapidez das transformações e novas demandas, destaca a fragilidade do trabalho isolado e aponta para a necessidade do trabalho em rede e da cooperação, para potencialização da produtividade e competitividade. Conforme afirma Dias Sobrinho (2007), diante do contexto de alta produtividade movido pela rapidez das mudanças, não é mais suficiente preparar para o trabalho, mas de continuamente promover o desenvolvimento das possibilidades de novas aprendizagens e adaptação às mudanças no mundo do conhecimento, do trabalho e da vida social.

No entanto, é pertinente destacar que há visivelmente a preocupação de preservar o sentimento de pertencimento a um determinado espaço comum, por meio da preservação dos valores e sua história da sociedade Europeia, ou seja, diante as demandas pela produtividade, inovação e competitividade a cultura europeia deveria ser preservada e cultivada pois constitui a identidade de seu povo e ainda é referência mundial pelas suas conquistas, avanços e desenvolvimento nas artes, ciência e filosofia. Parece ser com essa preocupação que o documento destaca a centralidade, reconhecida universalmente, do ensino e da cooperação pedagógica, como pilares de sustentação e fortalecimento de "sociedades estáveis, pacíficas e democráticas", isto é, não se constrói uma Europa do Conhecimento competitiva, atraente e valorizada localmente e globalmente, sem um processo educativo voltado para o enfrentamento das demandas oriundas de um novo contexto econômico global interdependente e interconectado e para preservação e valorização de sua histórica. Além disso, tal construção é possível, acima de tudo, pela produção material e intelectual de seus cidadãos, por meio do acesso ao conhecimento e oportunidades de trabalho. Destaca-se, no entanto, que ao lado da valorização da cultura europeia há a demanda de inserir-se no espaço competitivo global e uma das maneiras de fazer isso era contar com a Universidade Europeia, já que as bases da economia estavam assentadas no desenvolvimento tecnológico, o que demanda novos olhares para as instituições produtoras de conhecimento e formadoras de profissionais.

O documento destaca ainda que, de um lado, houve a disposição de vários países na busca pelos objetivos propostos, demonstrando a determinação dos governos em agir; e de 
outro, que as instituições europeias de ensino superior, também propuseram-se a aceitar o desafio e "assumiram um papel preponderante na criação do Espaço Europeu do Ensino Superior” (DECLARAÇÃO DE BOLONHA, 1999, p.1). A disposição das instituições de ensino é considerada de máxima importância, já que "a independência e a autonomia das Universidades asseguram que o ensino superior e os sistemas de estudo, se adaptem às necessidades de mudança, às exigências da sociedade e aos avanços do conhecimento científico" (DECLARAÇÃO DE BOLONHA, 1999, p.1). Segundo Sobrinho (2007, p. 111) "as autoridades educacionais europeias perceberam que a construção de uma Europa competitiva e unida passa necessariamente pela consolidação e convergência na educação superior”. No entanto, a adesão das Universidades por meio de seus sujeitos, não foi assim tão tranquila e livre de tensões nos países europeus, promovendo rupturas, críticas, tensões e resistências.

As linhas redigidas no documento afirmam que o "rumo foi traçado na direção certa e com um objetivo significativo", a saber "aumentar a competitividade no Sistema Europeu do Ensino Superior, já que a vitalidade e a eficiência de qualquer civilização podem ser medidas através da atração que a sua cultura tem por outros países" (DECLARAÇÃO DE BOLONHA, 1999, p.1). Assim, o Espaço Europeu do Ensino Superior deveria, a curto prazo, levar adiante as seguintes premissas:

a) Adotar um sistema com graus acadêmicos de fácil equivalência, sendo uma das estratégias o Suplemento ao Diploma a fim de promover a empregabilidade dos cidadãos europeus e a competitividade do Sistema Europeu do Ensino Superior.

Nessa primeira premissa fica evidente a preocupação com a formação para a empregabilidade, já que o emprego é fundamental para o desenvolvimento econômico e social, assim como, a equiparação e equivalência dos graus acadêmicos, tornaria o Sistema Europeu de Ensino Superior atrativo, sejam pelas facilidades burocráticas, quanto pela qualidade e diferenciação da formação oferecida.

b) Adotar um sistema de ensino com duas instâncias: graduação e pós-graduação. A duração da primeira seria de três anos, constituindo-se como condição de acesso à segunda e habilitando para o ingresso no mercado de trabalho. A segunda consistiria nos estudos de mestrado e doutorado, como já acontecia em muitos países europeus.

Nessa segunda premissa, há a preocupação com a eficiência e rapidez do tempo de formação, sendo para isso necessária a redução para três anos da formação na graduação, desse modo integrando o mercado de trabalho mais rapidamente, assim como, também aligeirando o acesso ao nível da pós-graduação.

c) Criar um sistema de créditos como estratégia para potencializar a mobilidade de estudantes, tornando-a o mais livre possível. Os créditos poderiam ser obtidos em outros contextos além do ensino superior, oportunizando a inclusão de aprendizagens feitas ao longo da vida, porém deveriam ser reconhecidos pelas Universidades credenciadas. Percebe-se a preocupação de resolver o problema da adaptabilidade dos currículos, de modo a tornar mais efetiva e facilitar a mobilidade dos estudantes nas instituições de ensino europeias. Porém abre-se espaço para a valorização de outras aprendizagens feitas para além das instituições de 
ensino, porém que deveriam passar pela validação das mesmas. Se de um lado, há a preocupação em aproveitar a potencialidade da diversidade de espaços de formação alternativos e que contribuíram para a formação profissional de seus cidadãos, assim como, de apreender novas demandas e soluções para os problemas emergentes, ampliando o repertório de conhecimentos para além da academia; por outro, há a preocupação com a validação desses conhecimentos, ou seja, com o seu reconhecimento como conhecimentos socialmente e academicamente válidos. Por isso, precisa-se da validação das Universidades, ou seja, não estamos diante de um 'vale tudo', mas de validação de experiências formativas.

d) Incentivar a mobilidade por etapas no exercício útil que é a livre circulação, com atenção especial aos estudantes e professores. Em relação aos estudantes o objetivo é garantir o acesso a oportunidades de estudos, estágios e serviços a eles relacionados; em relação aos professores, investigadores e pessoal administrativo o objetivo era oportunizar o reconhecimento e valorização dos períodos dedicados a ações Europeias de pesquisa, docência e formação. Aqui fica evidente a preocupação com a mobilidade de estudantes, professores e demais profissionais da educação, de modo a potencializar o intercâmbio de conhecimentos e práticas pedagógicas e profissionais. Evidencia-se a iniciativa de tornar mais efetiva e orgânica a cooperação entre as instituições de ensino superior, de modo a potencializar a produção do conhecimento.

e) Incentivar à cooperação Europeia na busca pela garantia da qualidade com o objetivo de desenvolver critérios e metodologias comparáveis;

Nessa premissa destaca-se a preocupação com a cooperação para a busca pela qualidade, já que é ela que elevaria os graus de notoriedade e interesse mundial pela Europa. Com o desenvolvimento de critérios e metodologias comparáveis, se poderia aumentar substancialmente os níveis de qualidade da formação e de produção de conhecimento, consolidando a coerência, atratividade e competitividade do Sistema Europeu de Ensino Superior. De posse de critérios e metodologias qualificados seria possível intervir para a melhoria, assim como, agregar conhecimento pela cooperação mútua entre as instituições, pesquisadores e estudantes.

f) Promover as necessárias dimensões no ensino superior Europeu em relação ao desenvolvimento curricular, cooperação interinstitucional, projetos de circulação de pessoas, programas integrados de estudo, de estágio e de investigação.

Nessa última premissa, destaca-se a preocupação de que a grande reforma em busca da qualidade e da competitividade não acontecerá no vazio, que as instituições precisarão se reorganizar de modo a dar conta das novas demandas, desse modo, implicando no realinhamento de suas propostas pedagógicas e curriculares, assim como de parceiras interinstitucionais, circulação de pessoas e propostas de integração entre formação, mercado de trabalho e pesquisa.

Para atingir tais objetivos será respeitada a diversidade das culturas, línguas, sistemas de ensino nacionais e a autonomia das Universidades, a fim de consolidar o Espaço Europeu do Ensino Superior. É nessa direção que afirmada a direção do caminho a seguir: "seguiremos os caminhos da cooperação inter-governamental, em conjunto com as organizações europeias não-governamentais que tenham autoridade no campo do ensino

\begin{tabular}{l|l|l|l|l|l|l} 
(C) Rev. Inter. Educ. Sup. & Campinas, SP & v.1 & n.2 & p.182-198 & out./dez. 2015 & ISSN 2446-9424 \\
\hline
\end{tabular}


superior" (DECLARAÇÃO DE BOLONHA, 1999, p.2). Desse modo, é esperado das Universidades prontidão e contribuição ativa para a garantia do sucesso da proposta.

Nesse sentido, é possível afirmar que a Declaração de Bolonha consiste numa proposta de política pública para a educação superior europeia, para dar conta das novas demandas impostas por um modelo de desenvolvimento globalizado onde impera a busca constante pela inovação e competitividade interna e externa. No entanto, precisam ser feitos ajustes nas instituições de ensino superior para que garanta a produção de novos conhecimentos de modo cooperativo, já que isoladamente diante das novas conjunturas de desenvolvimento tecnológico é inviável, buscando o intercâmbio constante de conhecimento e pessoas, de modo a promover tanto a formação para o trabalho e a necessidade de novas oportunidades de emprego, como da pesquisa cooperativa. Fica evidente que para o enfrentamento dos problemas econômicos e políticos as instituições de ensino superior são uma 'peça-chave' pois são as principais formadoras de profissionais e produtoras de conhecimento pela pesquisa. No entanto, o perigo da lógica acadêmica sucumbir diante da lógica econômica-mercadológica é eminente, e as instituições de ensino superior, tanto na Europa como nos demais continentes, não passam imunes por essa pressão. Exemplo disso é o aligeiramento do tempo de formação voltado exclusivamente para a lógica do mercado de trabalho, que está presente na Declaração de Bolonha e nas políticas de expansão do ensino superior brasileiro. A seguir apontaremos quais são os traços possíveis, tanto de aproximação quanto de diferenciação, da Declaração de Bolonha e as políticas de expansão da Educação Superior.

A influência da Declaração de Bolonha nas políticas de expansão da Educação Superior no Brasil.

Frente à tendência hegemônica liberal representada pela globalização, a Universidade pública mostra-se também como um espaço que preserva a pluralidade da pesquisa. A grande questão é a de saber como as novas lutas de emancipação em prol da defesa dos interesses da maioria vão atuar para combater os efeitos perversos da globalização, que cria novas formas de exclusão ao mesmo tempo em que acentua os antigos modos de exploração. Contudo, uma coisa é certa, a eficácia dos movimentos libertários passa pelo manejo da informação e do domínio das novas tecnologias, pois nisso reside a nova forma de expansão do capital. A luta tende a ser cada vez mais em torno da informação: o controle das técnicas de produção passa pelo controle das tecnologias de informação. A Universidade pública pode ser o único espaço em que as tendências emancipatórias podem ter acesso às novas tecnologias. Destruí-la significa cortar de forma brutal as possibilidades de resistências, principalmente nos países em que a globalização é imposta de forma unilateral pelos "globalizadores". 


\section{CONSIDERAÇÕES FINAIS: A UNIVERSIDADE NO CONTEXTO DA GLOBALIZAÇÃO NEOLIBERAL}

A partir dos anos oitenta percebe-se a intensificação do número de alianças estratégicas de cooperação científica e técnica entre universidade e indústria. Trata-se de um processo de globalização de Pesquisa \& Desenvolvimento. Conforme mostra Licha (1996), as alianças podem se dar através de participação acionária e não-acionária, bem como através de consórcios para fazer investigação pré-competitiva, mais genérica do que aplicada e ainda acordo de investigação básica e cooperação técnica.

Ao participar do sistema de financiamento da pesquisa, os setores do mercado atuam de modo a influenciar e a "subsanar certas ineficiências do sistema de pesquisa acadêmica com respeito a necessidades das indústrias" (LICHA, 1996, p. 121). Trata-se de orientar a Academia para a pesquisa "pre-competitiva", isto é, para proporcionar os fundamentos para o desenvolvimento de novos produtos, processos e serviços exigidos pelas empresas. A principal consequência desse processo é a perda da autonomia e da capacidade crítica da Universidade para produzir novas ideias e conhecimentos. Ela se transforma em uma instituição subordinada a outra dinâmica de interesses totalmente diversos dos seus próprios fins.

Licha (1996), seguindo a bipartição proposta principalmente por Gibbons, destaca dois modelos de Academia: o tradicional e o globalizado. No padrão tradicional a pesquisa científica referir-se-ia aos interesses da comunidade acadêmica, em que prevaleceria a disciplina, a homogeneidade e um sistema próprio de hierarquia, centralizado no departamento. Já no padrão determinado pela globalização da Universidade os interesses da mesma tornam-se extra-acadêmicos. Agora passa a operar um sistema baseado na transdisciplinaridade, heterogeneidade, em que estaria ausente a hierarquia, pois organiza-se segundo equipes flexíveis, ou seja, que se constituem conforme os objetivos momentâneos dos projetos voltados para satisfazer as exigências do mercado. Nas próprias palavras de Licha (1996, p.123) temos que a forma do novo padrão de Academia "é socialmente mais quantitativo e participam nos conjuntos heterogêneos de investigadores que colaboram num contexto específico e localizado". Neste último padrão, a pesquisa baseia-se em centros "adstritos" aos Departamentos, funcionando de forma independente. Surgem então conflitos ligados à questão da autonomia e ao controle dos recursos entre os diferentes Centros e os Departamentos. Essa nova tendência hegemônica da Universidade globalizada redefine a estrutura da organização da pesquisa na Academia, processo no qual estariam envolvidas as áreas ligadas às ciências humanas.

Licha (1996) destaca os argumentos a favor e os contrários a intensificação da relação da Universidade com a empresa. Segundo os primeiros, a confiança na universidade pode ser restabelecida, pois ela tende a contribuir para o crescimento econômico e a competência da economia no mundo globalizado, uma vez que ela tenderá a produzir mais o conhecimento 
útil, aplicável. Admite também a possibilidade de a Universidade buscar financiamento junto ao mercado sem prejudicar a liberdade e a qualidade acadêmica. Os que são contrários à intensificação do vínculo Universidade-empresa argumentam que isso levaria a instituição a ser controlada pelas tendências do mercado, o que restringiria a responsabilidade social da pesquisa. A própria Academia passaria a ser regida pela lógica do mercado: produzir o máximo de investigação prática, com o menor tempo possível.

$\mathrm{Na}$ medida em que as Universidades tendem a se moldar conforme as exigências do mercado, no sentido de se tornarem mais competitivas, suas estruturas internas vão se transformando.

Se a lógica inerente ao projeto neoliberal consiste em desenvolver um ser humano flexível, competitivo, que consome e se adapta às regras de mercado, é possível imaginar que a construção de um projeto educacional e pedagógico tende a valorizar o conhecimento a partir da noção de multiplicidade cultural, cuja valorização da diversidade social positiva escamoteia a essência exploratória das relações capitalistas que se consolida exatamente através da manutenção dos "despossuidos". Ou seja, a lógica se pauta na manutenção da propriedade privada, do caráter liberal, que pretende considerar todos como proprietários. $\mathrm{O}$ conflito capital-trabalho, neste aspecto, está obscurecido pela lógica da igualdade de condições - a capacidade de troca. E a Universidade está atualmente inserida nesse universo, o que pode ser constatado ao analisarmos os pontos destacados acima a respeito da Declaração de Bolonha e da expansão da Educação Superior Brasileira.

A valorização do plano "micro", das especificidades sociais, traz uma contribuição no sentido de compreender aspectos da formação social contemporânea, elementos estes, essenciais para que se possa superar os limites de uma concepção de homem para além do sujeito ariano, masculino, europeu.

Vale a pena destacar que as práticas que ocorrem nas instituições de educação superior nos remetem a heterogeneidade e a uma diversidade de níveis de sujeitos e de Universidades, em cada conjunto de atividades seja de ensino, seja de pesquisa ou de extensão.

Parece-nos que reside ai a possibilidade de que os educadores se coloquem como Sujeitos da História. Contraditoriamente o processo de socialização que se realiza nas instituições de educação superior, regulada pelo Estado, pode voltar-se também, para o desenvolvimento do ser humano, pode ser mediador, em termos da formação dos indivíduos, entre a vida cotidiana e as esferas formais da reprodução social.

Não nos colocamos aqui de forma idealista. A crescente complexificação das relações reificadas que se realizam sob os cânones do capitalismo, acentuam a tendência de naturalização destas relações sociais que são históricas. Premidos pela economia de tempo, os Sujeitos tendem, na vida cotidiana, a pautar suas escolhas, a estabelecer suas alternativas

\begin{tabular}{l|l|l|l|l|l|l} 
(C) Rev. Inter. Educ. Sup. & Campinas, SP & v.1 & n.2 & p.182-198 & out./dez. 2015 & ISSN 2446-9424
\end{tabular}


orientados pelo que se apresenta imediatamente. Existe uma dificuldade real em demarcar os constituintes históricos do desenvolvimento social, o que fortalece a inércia, a manutenção do status quo, sob o aparente revolucionamento constante das condições de vida. Por isso a insistência no resgate à história, o que exigiria um tempo de distanciamento para entrar em contato com a produção histórica da humanidade, como genericidade.

O desafio que se coloca para os educadores, é compreender em que medida o seu trabalho pode ou não aprofundar os processos de desumanização, negando portanto a possibilidade de formação humana no sentido de sua genericidade, ou ao contrário, propiciar a realização dos sujeitos na sua genericidade.

A partir dessas considerações, tornamos pública nossa preocupação para com as afirmações e explicações teórico-metodológicas, que propõem o combate ao conhecimento racional moderno. Se, segundo alguns desses pressupostos a prerrogativa de que a racionalidade moderna aproxima-se do mito, da falência ou insuficiência da racionalidade moderna, torna-se evidente e necessário investir na construção de um conhecimento que abranja a especificidade do indivíduo, valorizando-se sua subjetividade, através da linguagem e da comunicação.

Frente à investida de setores organizados da sociedade contra a Universidade pública, percebe-se que as diretivas das instituições nacionais são produtos de uma luta ideológica a fim de que determinadas tendências hegemônicas prevaleçam. Prevalecerão as tendências que forem assumidas pela opinião pública como as mais importantes para o país. A tendência que tem prevalecido é a da flexibilização e privatização. Com isso impõe-se a ideia de que a Universidade não pode mais depender do financiamento público e que as pesquisas necessitam de parcerias com o mercado para se manterem.

Cabe aos intelectuais comprometidos com uma Universidade pública plural lutarem para reverter essas tendências ${ }^{12}$. Mas, semelhante luta envolve uma plataforma de combate muito ampla formando uma frente capaz de impor novas tendências para as instituições nacionais, as quais podem apresentar-se como alternativas para a globalização subordinada.

A nova tendência hegemônica que se imporá às Universidades dependerá do embate entre correntes ideológicas e políticas. Frente à essa luta hegemônica, o pesquisador pode se restringir a ser um mero agente da "técnica-lavoro" visando adaptar-se ao mundo globalizado

\footnotetext{
${ }^{12}$ Trata-se de uma tendência perversa, ideológica, que segundo Licha esconderia uma falácia segundo a qual basta seguir as regras do jogo da globalização para se dar bem. "El fin de las políticas competitivas en los países en desarrollo es primordialmente ideológico, ya que, por una parte, encubren el interés monopólico que impulsa y dicta tal política, y por la ostra, crean la ilusión de que todos los países que se someten a las nuevas reglas del juego tienen grandes e iguales oportunidades de salir victoriosos en esta contienda tecno-económica. Lo que en realidad ocurre es que a través de estos procesos de globalización se monopoliza la economía, se corporativizaprivatiza la producción del conocimiento y se reordenan las relaciones socioeconómicas entre países y regiones, de acuerdo a un nuevo patrón que exacerba las disparidades e inequidades propias del viejo modelo" ( LICHA, 1996, p. 211)
} 
e às transformações dele decorrentes. Eles são intelectuais orgânicos não enquanto intelectuais pesquisadores, mas como defensores das novas tendências, portanto, são intelectuais vinculados à classe dominante, às elites privilegiadas com a globalização. Em contrapartida a essa posição, o pesquisador pode se colocar como agente de transformação capaz de identificar as contradições e as estratégias perversas que ameaçam a dimensão crítica e autônoma da Universidade.

\section{REFERÊNCIAS}

BARREYRO, Gladys Beatriz; LAGORIA, Silvana Lorena. Acreditação na educação superior na América Latina cos casos da Argentina e do Brasil no contexto do Mercosul. Disponível em: 〈http://www.usp.br/prolam/downloads/2010_1_1.pdf.>. Acesso em: 17 ago. 2015.

BUARQUE, Cristovan. A universidade na encruzilhada. In: APPEL, Emmanuel. A Universidade na encruzilhada. Brasília: Unesco Brasil, 2003. p.23-66

DECLARAÇÃO DE BOLONHA. 1999. Disponível em: <http://www.ispa.pt/NR/rdonlyres/7AECBFAD-6B1A-4153-B61E5BA122E02D42/0/Declara\%EF\%BF\%BD\%C3\%A3odeBolonha1.pdf >. Acesso em: 15 ago. 2015 .

DIAS SOBRINHO, José. O processo de Bolonha. In: PEREIRA, E. M. A.; ALMEIDA, M. L. P. Universidade contemporânea: políticas do processo de Bolonha. Campinas: Mercado de Letras, 2009.

FERREIRA, Suely. Reforma da educação superior no Brasil e na Europa em debate novos papeis sociais para as Universidades. Disponível em:

http://www.anped.org.br/33encontro/app/webroot/files/file/Trabalhos\%20em\%20PDF/GT116003--Int.pdf>. Acesso em: 15 ago. 2015.

FRIEDMAN, M. Capitalismo e liberdade. Brasilia: Ed. Arte Nova, 1977.

GANDAL, K. Michel Foucault: trabalho e política. Revista de História, n. 1, p.108-109, 1989.

GOERGEN, Pedro. A avaliação universitária na perspectiva da pós-modernidade. In: DIAS SOBRINHO, J. D; RISTOFF, D. I. (Org.) Universidade desconstruída: avaliação institucional e resistência. Florianópolis: Insular, 2000.

GRAMSCI, A. Os intelectuais e a organização da cultura. 9.ed. Rio de Janeiro: Civilização Brasileira, 1995.

Concepção dialética da história. Rio de Janeiro: Civilização Brasileira, 1995.

HAYEK, F. O caminho da servidão. 2.ed. Porto Alegre: Ed. Globo, 1977.

HARVEY, David. Condição pós-moderna. São Paulo: Edições Loyola, 1992.

\begin{tabular}{l|l|l|l|l|l} 
C C Rev. Inter. Educ. Sup. & Campinas, SP & v.1 & n.2 & p.182-198 & out./dez. 2015
\end{tabular} 
LEITE, Denise; GENRO, Maria Elly H. Avaliação e internacionalização da educação superior: Quo vadis América Latina?, Avaliação, Sorocaba, v.17, n.3, nov. 2012.

LICHA, I. La investigación y las universidades latino-americanas en el umbral del siglo XXI: los desafíos de la globalización. Ciudad: UDUAL, 1996. (Coleccíon UDUAL; 7).

LIMA, Licínio C.; AZEVEDO, Mário Luiz Neves; CATANI, Afrânio Mendes. O processo de Bolonha, a avaliação da educação superior e algumas considerações sobre a Universidade Nova. Avaliação, Sorocaba, v.13, n.1, p.7-36, 2008.

MARX, Karl. Contribuição à crítica da economia política. São Paulo: Martins Fontes, 1977.

. Teses sobre Feuerbach (III). In: MARX, Karl; ENGELS, Friedrich. Textos. São Paulo: Edições Sociais, 1977. v.3.

O capital. São Paulo: Nova Cultural, 1985. v.3.

NEVES, Clarissa Eckert Baeta Neves. Reforma e desafios da educação superior: o processo de Bolonha dez anos depois. Disponível em: <www.revistappgsa.ifcs.ufrj.br/pdfs/ano1v1_ artigo_clarissa-neves.pdf $>$. Acesso em: 17 ago. 2015.

PENA-VEJA, Alfredo. O processo de Bolonha no Ensino Superior da América Latina. Disponível em: <http://www.gulbenkian.pt/media/files/agenda/eventos_2009/Futuro\% 20de\%20Bolonha/TRADUCTION_PROCESSO_BOLONHA_FINAL-4.pdf $>$. Acesso em: 17 ago. 2015.

PEREIRA, E.M.A; ALMEIDA, M.L.P. Universidade contemporânea: políticas do processo de Bolonha. Campinas Mercado de Letras, 2009.

RAMA. K. Teoría de la historia. Madrid.Editorial Tecnos, p. 93, 1974.

SAVIANI, D. Educação e questões da atualidade. São Paulo: Livros do Tatu/Cortez, 1991.

SIEBIGER, Ralf Hermes. Influências do processo de Bolonha europeu nas políticas de educação superior brasileiras e na criação de Universidades federais. Disponível em: $<$ http://www.anpae.org.br/simposio2011/cdrom2011/PDFs/trabalhosCompletos/comunicacoe sRelatos/0447.pdf>. Acesso em: 17 ago. 2015.

SILVA JUNIOR, J. R.; SGUISSARD, V. Novas faces da educação superior no Brasil. Braga Paulista, EUDUSF, 1999.

SMITH, A. A riqueza das nações. Vol. I. São Paulo: Nova Cultural, 1985.

Processo de Bolonha. ETD - Educação Temática Digital, Campinas, v.9, n. esp., p.107-132, dez, 2007.

VELHO, S. Relações Universidade-Empresa: desvelando mitos. São Paulo: Autores Associados, 1996. 